\title{
MAPEAMENTO DE PROCESSOS PRODUTIVOS NA INDÚSTRIA DE CALCÁRIOS CAÇAPAVA LTDA
}

\author{
Edson Batista Marques ${ }^{1}$, Leandro Dorneles dos Santos ${ }^{2}$
}

RESUMO: A análise dos processos produtivos é vista, atualmente, como a principal rotina para alcançar a redução de custos, o aumento da produtividade e a melhoria contínua dentro das organizações. Por isso, o objetivo desta pesquisa foi analisar e documentar o mapeamento de processos da produção de calcário na Indústria de Calcário Caçapava LTDA. Assim, o método utilizado caracterizou-se como pesquisa descritiva, com análise qualitativa dos dados, com técnicas de pesquisa documental, observação e estudo de caso. Utilizou-se a entrevista semiestruturada como ferramenta para a coleta dos dados, aplicada junto ao Administrador de operações da empresa em novembro de 2018, e o tratamento deu-se através da técnica de análise de conteúdo. Como resultado, a partir das análises realizadas, apresenta-se o diagrama do processo de produção de calcário da empresa alvo, desenhado em conformidade com padrão Business ProcessModelingNotation(BPMN).

Palavras-chave: Mapeamento. Processos. Extração. Calcário. BPMN.

Submissão: $16 / 06 / 2020$

Aceite: $28 / 09 / 2020$

DOI:10.47591/RAC.2674-9203.2020v2n2.art2-16-31

\section{(c) (1) (9)}

Este trabalho está licenciado com uma Licença Creative Commons Atribuição-NãoComercial 4.0 Internacional.

1 Bacharel em Administração pela Faculdade Integrada de Santa Maria (FISMA). E-mail: edsonnicadudamanu@gmail.com

${ }^{2}$ Mestre em Gestão Estratégica de Organizações pela Universidade Regional Integrada - URI Santo Ângelo. Professor nos cursos de Administração e Gestão comercial da FISMA. E-mail: leandro.dorneles@fisma.com.br 


\section{INTRODUÇÃO}

No atual contexto mercadológico mundial, o ambiente de competitividade faz com que as empresas busquem cada vez mais um contínuo aperfeiçoamento da gestão de seus recursos e a eliminação de desperdícios no processo produtivo, em diversas áreas.

Destaca-se que para entender os processos de uma organização, é necessário realizar o mapeamento dos mesmos e, para que isso seja feito de forma eficiente, é preciso ter um completo entendimento sobre suas atividades tanto documentais quanto operacionais, a aplicabilidade e a combinação de técnicas de mapeamento de processo para assim agregar valor, qualidade ao produto final e uma maior rentabilidade financeira, pois estes garantiram o diferencial e a permanência no mercado e consequentemente um maior reconhecimento do consumidor final (AMORIM; ROCHA 2012).

Moreira (2011) contextualiza que no Brasil, a gestão de processos da produção nas empresas vem se tornando cada vez mais importante em uma cultura globalizada. Afirma ainda que, sem as ferramentas gerenciais ou sem a eficiência do processo produtivo, dificilmente uma empresa vai ser bem-sucedida ou até mesmo sobreviver no mercado. Assim, em uma organização a gestão dos processos e as atividades são os meios de agregação de valores aos produtos e serviços para o atendimento das expectativas dos clientes (HUNT, 1996).

Assim sendo, cabe ressaltar que, atualmente, todos os segmentos industriais estão sob pressão devido à instabilidade econômica global. Muitas vezes essas empresas buscam amenizar essas volatilidades econômicas através da otimização de processos industriais a fim de baixar os custos operacionais e incrementar a produção. Isto é particularmente válido em empresas com processos de fabricação contínuos (OLIVEIRA, 2015).

Diante do exposto, esta pesquisa visa responder a seguinte questão problema: Como identificar, avaliar e documentar o mapeamento do processo produtivo em uma indústria de calcário? Para responder a esta questão, o objetivo geral do estudo foi analisar e documentar o mapeamento de processos na produção de calcário na Indústria de Calcário Caçapava LTDA, localizada na cidade de Caçapava do Sul, RS.

Como justificativa para realização deste trabalho de pesquisa, destaca-se que para os pesquisadores, o mesmo foi de grande valia no que tange à busca pelo entendimento sobre mapeamento do processo de produção de calcário e seus derivados e para a literatura, acredita-se que o mesmo possa acrescentar uma experiência exitosa de melhoria por meio do mapeamento de um processo.

Para a empresa alvo da pesquisa, a importância ocorre em razão da contribuição gerencial, já que pode possibilitar a busca por uma produção mais enxuta e rentável, proporcionando uma maior qualidade e competitividade de mercado, uma vez que, no Brasil, por exemplo, o aquecimento no setor civil e agropecuário ocasionou aumento da demanda no consumo de calcário agrícola. Segundo a Associação Brasileira de Produtores de Calcário Agrícola (ABRACAL), a 
região sul do país destaca-se por ser um dos maiores consumidores de calcário agrícola no cenário nacional (ABRACAL, 2015).

Já para o curso de Administração da FISMA (academia), entende-se que o presente estudo poderá contribuir para realização de estudos complementares, de maior profundidade no presente tema, além de proporcionar maior entendimento sobre mapeamento de processos e BPMN.

\section{REVISÃO TEÓRICA}

\subsection{GESTÃO DE PROCESSOS}

Quando se fala em Gestão de Processos Organizacionais, entende-se que os processos da instituição, empresa ou organização estão sendo monitorados, avaliados e revisados, com foco na melhoria contínua e no alcance dos objetivos e metas estabelecidos pela organização. (MARCONDES, 2015).

Segundo Usinoro, além da gestão de processos, surge a gestão por processos. "A gestão de processos indica que o objeto da gestão é o processo. Neste sentido, busca-se otimizá-lo efetuando a análise e a execução de ações com base em um determinado método escolhido para melhorar algum indicador de desempenho". (USIRONO, 2015, p. 23). Já a gestão por processos, segundo o mesmo autor, "Indica uma visão e uma cultura de atuação" (USIRONO, 2015, p. 23), ou seja, entende-se que a empresa é composta de um conjunto de processos integrados.

Complementa ainda que, cabe a gestão de processos operacionalizar os objetivos de negócio da empresa, interligando a organização com o ambiente externo e com o ambiente interno, a partir de um conjunto de atividades desenvolvidas por uma área especializada ou funcional. (USIRONO, 2015).

Ainda conforme Usirono (2015, p. 22), os processos tem como objetivos principais:

- Operacionalizar e otimizar recursos do sistema, buscando eficiência e eficácia em termos de desempenho do processo;

- $\quad$ Reduzir o número de erros ou falhas: a diminuição de erros afeta diretamente os custos do processo; além de aumentar a percepção do cliente sobre a qualidade de entrega para o cliente;

- Reduzir o tempo de execução;

- Reduzir o custo do processo é um dos fatores que tornam a empresa mais competitiva;

- Aumentar a produtividade, consequentemente a eficiência do processo utilizando menos insumos para conseguir os mesmos resultados;

- Reduzir riscos operacionais, ou seja, diminuir falhas de sistemas, equipamentos e erros humanos no nível de prevenção, avaliação e detecção;

- $\quad$ Aumentar o nível de segurança do processo: a segurança é um aspecto muito importante para a integridade, a confiabilidade e o sigilo das informações.

Surge, neste contexto, a necessidade de visão de processo. Enquanto a visão funcional focaliza a especialização, sustentada por forte estrutura hierárquica, a 
visão de processo enfoca o próprio trabalho, a fim de gerenciá-lo, e não a estrutura organizacional (OSTRENGA et al. 1993). Para atingir a vantagem competitiva almejada é preciso compreender e aperfeiçoar os processos através do mapeamento correto dos mesmos utilizando as ferramentas adequadas para cada processo dentro de uma cadeia de produção. (PINHO et al., 2007).

\subsection{MAPEAMENTO DE PROCESSOS}

Segundo Mello e Salgado (2005), para se gerenciar um processo é necessário, primeiramente, visualizá-lo. Assim, o mapeamento é realizado para representar as diversas tarefas necessárias e a sequência que elas ocorrem para a realização e entrega de um produto ou serviço.

Villella (2000, p. 50) afirma que os processos dentro das organizações nem sempre são visíveis e conhecidos e, sendo assim, "o mapeamento de processos seria uma ferramenta gerencial analítica de comunicação cujo objetivo seria ajudar a melhorar os processos existentes". Adair e Murray (1996), trazem que os processos para que gerem os melhores resultados, deverão ser acompanhados de um planejamento e monitoramento das atividades, para que as empresas gerem melhores resultados.

Leal, Pinho e Corrêa (2005, p. 5), elencam que os processos precisam ser mapeados a fim de:

- Expor os detalhes do processo de modo gradual e controlado;

- Encorajar concisão e precisão na descrição do processo;

- Focar a atenção nas interfaces do mapa do processo;

- Fornecer uma análise de processos poderosa e consistente com o vocabulário do design.

Na linguagem gráfica necessária ao mapeamento de processos encontra-se uma variedade de ferramentas de análise disponíveis para auxiliar o analista de processo. Estas ferramentas foram desenvolvidas durante um longo tempo, ocorrendo a adequação entre grupos de ferramentas e metodologias de mudança e reestruturação de processos, sendo que houve um desenvolvimento paralelo e mais rápido das ferramentas baseadas em computador. (JOHANSSON et al., 1995).

Conforme Mello e Salgado (2005), às técnicas de mapeamento, torna-se imprescindível para a seleção das técnicas adequadas para cada situação em que se necessita empregar o mapeamento de processos.

O Lean Manufacturing (LM), ou Lean Production (LP), é tão relevante hoje para produção e sistemas de produção em massa como era no início do século XX. 0 LM pode ser considerado como uma abordagem sistemática para identificação e eliminação de perdas por meio da melhoria contínua e sincronização dos processos de produção, de tal forma que o fluxo de produtos utilizado para o clienterealizar um pedido tenha foco na qualidade e excelência da produção. (MAHAPATRA; MOHANTY, 2007).

As ferramentas gerenciais que podem ser aplicadas são de extrema importância para as organizações com processos produtivos, contínuos a fim de 
manter ou melhorar a competitividade. Contudo, algumas ferramentas de gestão foram adaptadas com sucesso aos processos produtivos contínuos, com o objetivo de melhorar as organizações a fim de atingir a excelência operacional. Uma delas, é o mapeamento de processos baseado no modelo BPMN, que em 2004 tomou a notação de modelagem de processos de negócios padrão. (BROCKE; ROSEMANN, 2013).

\subsection{BUSINESS PROCESS MODELING NOTATION}

Segundo Dubray (2004), o BPMN vem procurando achar a melhor maneira para a criação de uma notação intuitiva, usando construções familiares e um conjunto de regras comuns em processos de negócio. Neste sentido, Bortoline (2006) afirma que o BPMN é uma representação gráfica que tem por objetivo prover instrumentos para mapear, de uma maneira padrão, todos os processos de negócio da organização; e deve ser compreendido por analistas de negócio, técnicos e usuários integrantes dos sistemas.

Notação pode ser definida como uma escrita simplificada ou abreviada por meio de um conjunto de sinais abreviados. (LUFT, 2013). No entanto, diferenciandose de outros métodos,

[...] o Business Process Modeling Notation (BPMN) é um padrão desenvolvido visando oferecer uma notação mais facilmente compreendida e usada por todos os envolvidos nos processos de negócio; dos estrategistas e analistas de negócio (que criam versões iniciais dos processos) aos técnicos responsáveis pela seleção e implementação das tecnologias que apoiarão o gerenciamento e monitoramento desses processos. Trata-se de uma técnica abrangente e que oferece recursos para a modelagem dos mais variados tipos de processos, desde os mais genéricos aos específicos. Por isso, pode ser usada na modelagem de processos de qualquer tipo e natureza, como: administrativos (compras, vendas, controle de materiais etc.), financeiros (empréstimos, aplicações, controle de capital etc.), operacionais (manutenção, fabricação, distribuição etc.), garantia da qualidade, desenvolvimento de software, desenvolvimento de produtos ou de serviços. (VALLE, OLIVEIRA, 2015, p. 77).

A simbologia da BPMN permite criar Modelos de Processos de Negócio Business Process Diagrams (BPD) - para finalidades de documentação e comunicação. Esses modelos seguem uma notação padrão, desenvolvida pela The Business Process Management Initiative (BPMI) e foi lançada publicamente em maio de 2004.

A BPMN é uma notação que tem como propósito a geração de um diagrama de processos de negócio (BPD). O BPD é construído por meio de um conjunto básico de elementos gráficos. Estes elementos permitem o desenvolvimento de diagramas que são, normalmente, bastante familiares para a maioria dos analistas de negócio, pois são bastante parecidos com fluxogramas. (WHITE, 2004).

$\mathrm{Na}$ fase construtiva da modelagem de processos, deseja-se que as ferramentas utilizadas tenham as características descritas na Figura 1. 
Figura 1 - Características desejáveis para modelagem de processos

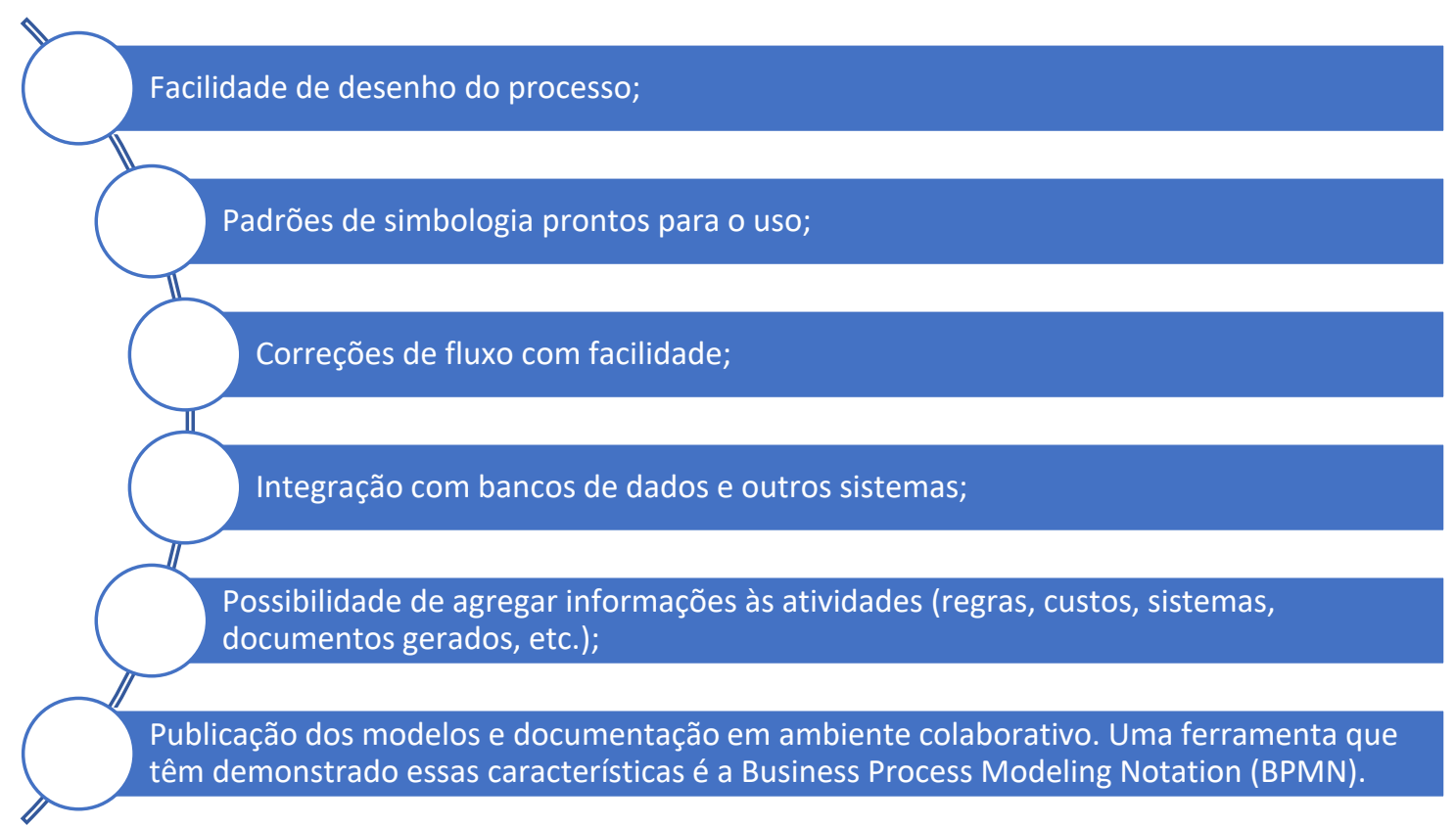

Fonte: Adaptado de Slack, Brandon-Jones e Johnston (2015).

BPMN.

Assim, no Quadro 1 são apresentados os elementos de fluxo básico da

Quadro 1 - Elementos de fluxo básico BPMN

\begin{tabular}{|c|c|}
\hline $\begin{array}{l}\text { REPRESENTAÇÃO } \\
\text { GRÁFICA }\end{array}$ & CARACTERÍSTICAS \\
\hline & $\begin{array}{l}\text { Símbolo de tarefa } \\
\text { É o nível mais básico de uma atividade e não pode ser subdividida. Por } \\
\text { exemplo, um processo de rotina matinal pode envolver a tarefa de } \\
\text { ligar seu computador. }\end{array}$ \\
\hline & $\begin{array}{l}\text { Gateway exclusivo } \\
\text { Dá seguimento ao fluxo por uma condição exclusiva, em que apenas } \\
\text { um dos caminhos será seguido de acordo com uma informação a ser } \\
\text { testada }\end{array}$ \\
\hline & $\begin{array}{l}\text { Símbolo de evento inicial } \\
\text { Sinaliza o primeiro passo de um processo. }\end{array}$ \\
\hline & $\begin{array}{l}\text { Símbolo de evento intermediário } \\
\text { Representa qualquer evento que ocorre entre um evento inicial e final. }\end{array}$ \\
\hline & $\begin{array}{l}\text { Símbolo de evento final } \\
\text { Sinaliza o passo final em um processo. }\end{array}$ \\
\hline & $\begin{array}{l}\text { Símbolo de fluxo de sequência } \\
\text { Conecta objetos de fluxo em uma ordem sequencial própria. }\end{array}$ \\
\hline $0-------\phi$ & Símbolo de fluxo de mensagem \\
\hline
\end{tabular}




\begin{tabular}{|c|c|}
\hline & Representa mensagens de um participante do processo para outro. \\
\hline 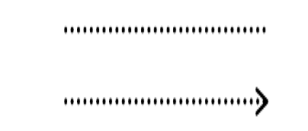 & $\begin{array}{l}\text { Associação } \\
\text { Uma associação é usada para associar informações e Artefatos com } \\
\text { Objetos de fluxo. }\end{array}$ \\
\hline 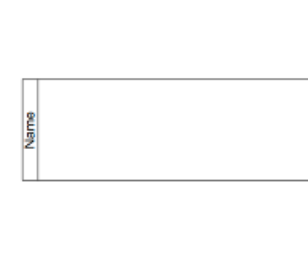 & $\begin{array}{l}\text { Swimlanes ou raias } \\
\text { É a representação gráfica da Colaboração entre Participantes. Um } \\
\text { Participante representa uma entidade parceira específica (por } \\
\text { exemplo, uma empresa) e/ou uma entidade genérica (por exemplo, } \\
\text { um comprador, vendedor ou fabricante). Uma Colaboração é uma } \\
\text { coleção de mensagens trocadas entre participantes. }\end{array}$ \\
\hline 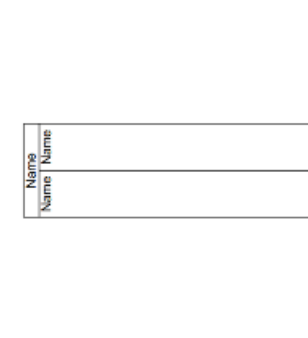 & $\begin{array}{l}\text { As raias são usadas para organizar os aspectos de um processo em um } \\
\text { diagrama BPMN. A raias agrupam os objetos visualmente em faixas, } \\
\text { com cada aspecto do processo adicionado a uma raia separada. Estes } \\
\text { elementos podem ser arranjados tanto horizontalmente como } \\
\text { verticalmente. As raias não apenas organizam as atividades em } \\
\text { categorias separadas, como também podem revelar atrasos, } \\
\text { ineficiências e os funcionários responsáveis por cada passo em um } \\
\text { processo. }\end{array}$ \\
\hline & $\begin{array}{l}\text { Objeto de dados } \\
\text { Conjunto de informações que é importante para a compreensão. }\end{array}$ \\
\hline $\begin{array}{l}\text { Descriptive Text } \\
\text { Here }\end{array}$ & $\begin{array}{l}\text { Anotação } \\
\text { A Anotação sempre vem associada a outro elemento por isso a figura } \\
\text { de anotação tem uma associação. }\end{array}$ \\
\hline 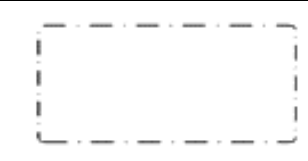 & $\begin{array}{l}\text { Agrupamentos } \\
\text { Grupos organizam tarefas ou processos que possuem relevância no } \\
\text { processo como um todo. }\end{array}$ \\
\hline$\square$ & $\begin{array}{l}\text { Mensagem } \\
\text { Aciona o processo, facilita processos intermediários ou finaliza o } \\
\text { processo. }\end{array}$ \\
\hline Atividacte do Envio & $\begin{array}{l}\text { Atividade de envio } \\
\text { É projetada para enviar uma mensagem para um participante externo } \\
\text { (em relação ao Processo). Uma vez que a mensagem foi enviada, a } \\
\text { tarefa é concluída. }\end{array}$ \\
\hline
\end{tabular}

Fonte: Venki (2016).

O BPMN foi projetado para cobrir muitos tipos de modelagem, permitindo criar um processo de negócio do início ao fim, conforme o conceito de um processo. Os elementos que compõe a estrutura do BPMN permitem que o leitor seja capaz de, com um certo nível de facilidade, ver e compreender seu processo de negócio no desenho (ARANTES, 2014).

A notação de modelagem possibilita a criação de processos de negócio ponta a ponta e é concebida para abranger várias atividades de modelagem restritas a esses processos. Os elementos estruturais de BPMN permitirão que o observador seja capaz de diferenciar seções de um diagrama de BPMN utilizando grupos, pools (piscinas) ou raias. Os tipos básicos de submodelo encontrados em um modelo de 
BPMN podem ser processos de negócio privados (internos), processos abstratos (públicos) e processos de colaboração (globais).

Rodriguez e Caro (2012) afirmam que o padrão além de grande expressividade é capaz de acomodar novas demandas, propostas na literatura, quanto ao gerenciamento de processos quanto a modelagem. Tais demandas incluem necessidades dos clientes: tempo, custo e confiabilidade, requisitos de segurança, explicitar restrições legais, desempenho do processo e qualidade de dados.

Recker (2010) destaca a importância da especificação gráfica dos negócios para a comunicação, redesenho do processo, ampliação e disseminação do conhecimento no âmbito da organização tornando seus colaboradores mais cientes de sua contribuição. Menciona, entretanto, que a modelagem consome uma quantidade considerável de recursos e tempo no âmbito da gestão por processos. Aponta as inúmeras notações criadas para servir a gestão de processos e em especial o BPMN, pois nenhum outro padrão teve uma aceitação tão rápida num curto período de tempo.

\section{MÉTODO}

O estudo realizado foi de natureza aplicada, descritiva e exploratória e, essencialmente, qualitativo. Quanto aos delineamentos, foram aplicadas as técnicasde pesquisa bibliográfica, documental, observação e, principalmente, estudo de caso.

A pesquisa bibliográfica, com o objetivo de oferecer suporte teórico ao estudo, baseou-se na análise dos artigos selecionados na base Scopus pelo método de Costa (2010), onde foram consultados trabalhos que versavam sobre o tema do estudo. A análise pretendeu apontar as características positivas e negativas do padrão de modelagem BPMN.

A pesquisa documental se deu nos materiais da empresa, principalmente sobre o processo produtivo de calcário. Já a observação se deu na área da produção, para entender e poder mapear todo o processo produtivo. A justificativa pela escolha do estudo de caso encontra-se no fato de existir uma lacuna quanto ao tema proposto e viabilizar, assim, uma visão mais clara acerca deste por meio de exploração sistemática e utilizando técnicas padronizadas de coletas de dados. (GIL, 2007), o que foi complementado pela pesquisa documental e observação.

Quanto ao instrumento utilizado para a coleta de dados, foi utilizada uma entrevista semiestruturada, tendo como referência o instrumento de coleta de dados proposto por Ribeiro et al. (2009). Para adequar o instrumento de coleta de dados ao estudo foram realizadas modificações em aspectos da estrutura original, compreendendo duas partes: a primeira busca identificar aspectos do perfil do entrevistado (idade, gênero, formação, tempo de experiência profissional na empresa, e tempo na organização).

Já a segunda parte, compreendeu questões abertas de modo a gerar os dados relacionados ao mapeamento dos processos na fabricação de calcário da empresa entrevistada, mais especificamente: Quais os insumos do processo? Qual a 
tecnologia empregada no processo produtivo? Quando o processo começa? Quando termina? Quando é avaliado? Como o processo é avaliado? Como o processo é controlado? Qual o mapa de processo utilizado atualmente? Observa-se que o instrumentocontinha questões direcionadas ao gestor responsável pelo setor de produção.

A entrevista foi aplicada junto ao Administrador de operações da empresa em novembro de 2018, com a gravação da conversa para posterior análise das informações. 0 tratamento dos dados foi executado por meio da técnica de análise de conteúdo. Conforme Bardin (2016, p. 37), a análise de conteúdo é um "conjunto de técnicas de análise das comunicações", sendo utilizada, neste caso, a técnica de descrição analítica. Buscou-se dessa forma, atender a realidade a ser pesquisada que era o mapeamento de processos produtivos na Indústria de Calcários Caçapava LTDA.

\section{ANÁLISE E DISCUSSÃO DOS RESULTADOS}

A empresa alvo da pesquisa foi a Indústria de Calcários Caçapava LTDA (INDUCAL), localizada na cidade de Caçapava do Sul, RS, com população estimada de 35.075 habitantes, com PIB de $\mathrm{R} \$$ 665.272.077, representando a indústria de transformação e a construção civil em torno de 10\% de participação no número de empresas por setor em 2015. (SEBRAE, 2017).

A INDUCAL possui atualmente três unidades industriais em operação tendo como os principais focos da organização os clientes envolvidos no agronegócio, a construção civil e indústria da cerâmica. A Figura 2 demonstra uma ideia do processo produtivo do calcário na empresa e de como funciona todo o seu procedimento desde aquisição da sua matéria prima até a venda do seu produto para seu cliente.

\subsection{MAPEAMENTO DO PROCESSO}

Após a entrevista e a análise de documentos disponibilizados pela empresa foi possível observar que a mesma possui um fluxograma unidirecional do processo de produção do calcário que permite-nos observar todo o processo de beneficiamento do calcário; desde do momento que se inicia a moagem da rocha bruta até o produto final pronto para ser comercializado.

A empresa em estudo possuio esquema ilustrado na Figura 2, para explicar o processo de britagem e rebritagem, sem que, no entanto, fosse possível entendelo para atingir esta função explicativa.

A partir do reconhecimento inicial da área a ser analisada, partiu-se para o mapeamento das atividades, quando após algumas visitas realizadas nas áreas em questão, pôde-se coletar todos os dados necessários por observação e pelas informações prestadas pelo gestor de operações, com o auxílio dos operadores e engenheiros que trabalham nestas células.

Observou-se que o processo da produção do calcário inicia-se com a perfuração da rocha e colocação de explosivos, que são dinamites de 2 in por $24 \mathrm{~cm}$ 
de comprimento com espoleta de $1,20 \mathrm{~m}$ de comprimento, para a detonação das rochas.

Figura 2 - Diagrama disponível sobre o processo de britagem e rebritagem do calcário

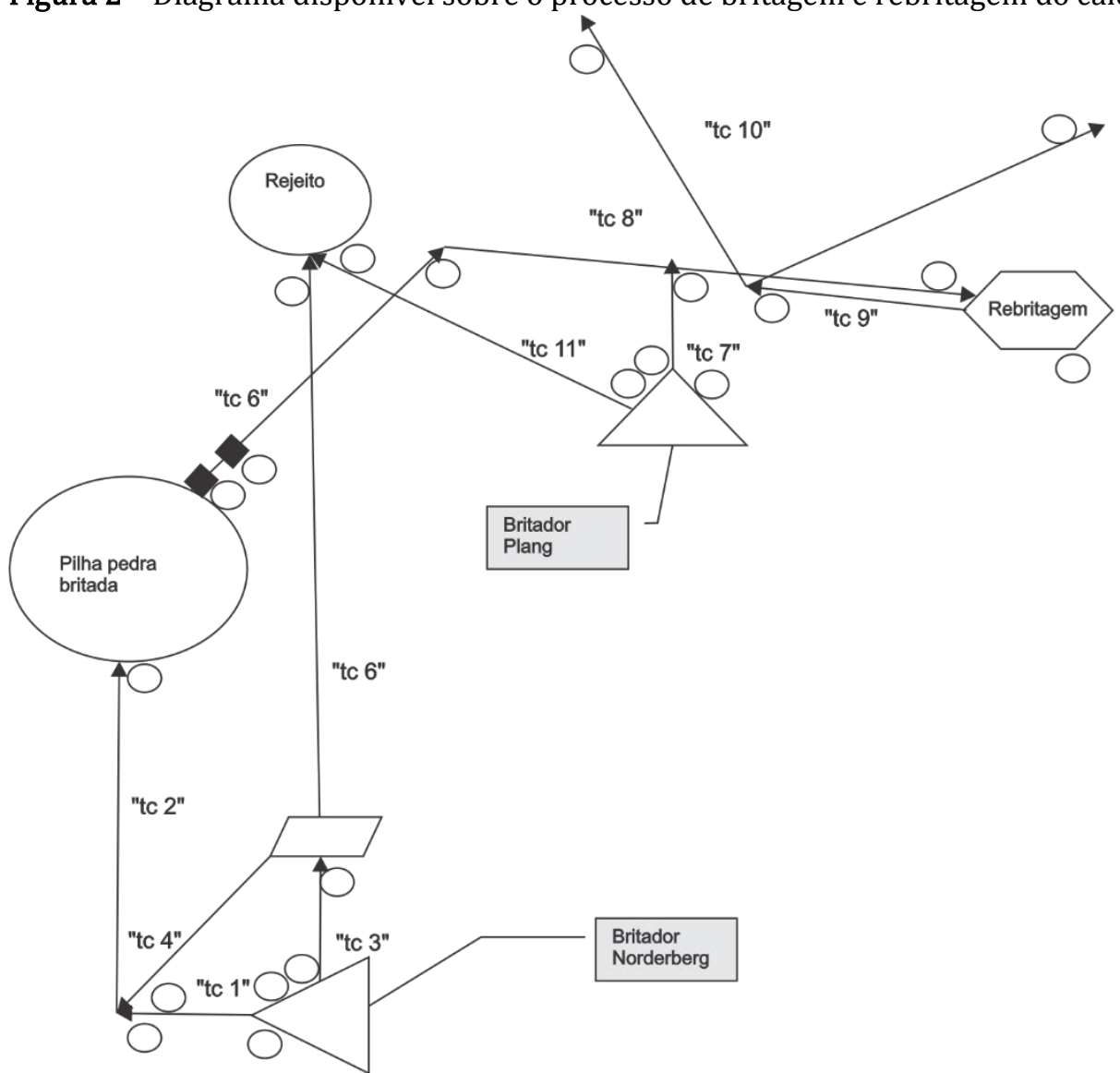

Fonte: Dados da pesquisa (2019).

Da mesma forma, o esquema apresentado, na Figura 3, representa o processo de moagem e peneiramento do calcário, sendo o mesmo de difícil entendimento por parte dos colaboradores e gestores. Assim, o estudo buscou entender o processo produtivo e a partir destas informações elaborar uma modelagem de processo através do BPMN, possibilitando assim uma melhor visualização e aplicação de uma ferramenta gerencial mais atual e de fácil entendimento.

A primeira fase do processo inicia-se quando as rochas são transportadas por caminhões e carregadeiras até o britador. Para iniciar a britagem do calcário, o operador de britagem liga um dos britadores primários (de acordo com a sua necessidade de produção), juntamente com as correias transportadoras (TC). Em seguida, é autorizada a descarga do caminhão com a emissão de um sinal sonoro, pelo operador de britagem. Então, a carga de pedra é descarregada na calha alimentadora pelo motorista.

Assim, inicia-se o processo de moagem inicial, demonstrado na Figura 2, onde o operador de britagem, sob a supervisão do encarregado geral de produção, determina o tipo de material a ser peneirado, por análise visual da carga. Quando há 
necessidade de peneiramento abre-se uma válvula na parte inferior do britador para a retirada do material menor de 4in, que é segregado pelos trilhos da calha do britador, este indo para peneira que separa a pedra do cascalho impróprio para calcário. A pedra selecionada cai em uma TC que leva o material até a TC da pilha do pulmão primário. 0 material maior que 4in passa por cima da calha para ser minimizado em uma dimensão menor que 8in.

Figura 3 - Diagrama disponível sobre o processo de processo de moagem e peneiramento do calcário

MOAGEM

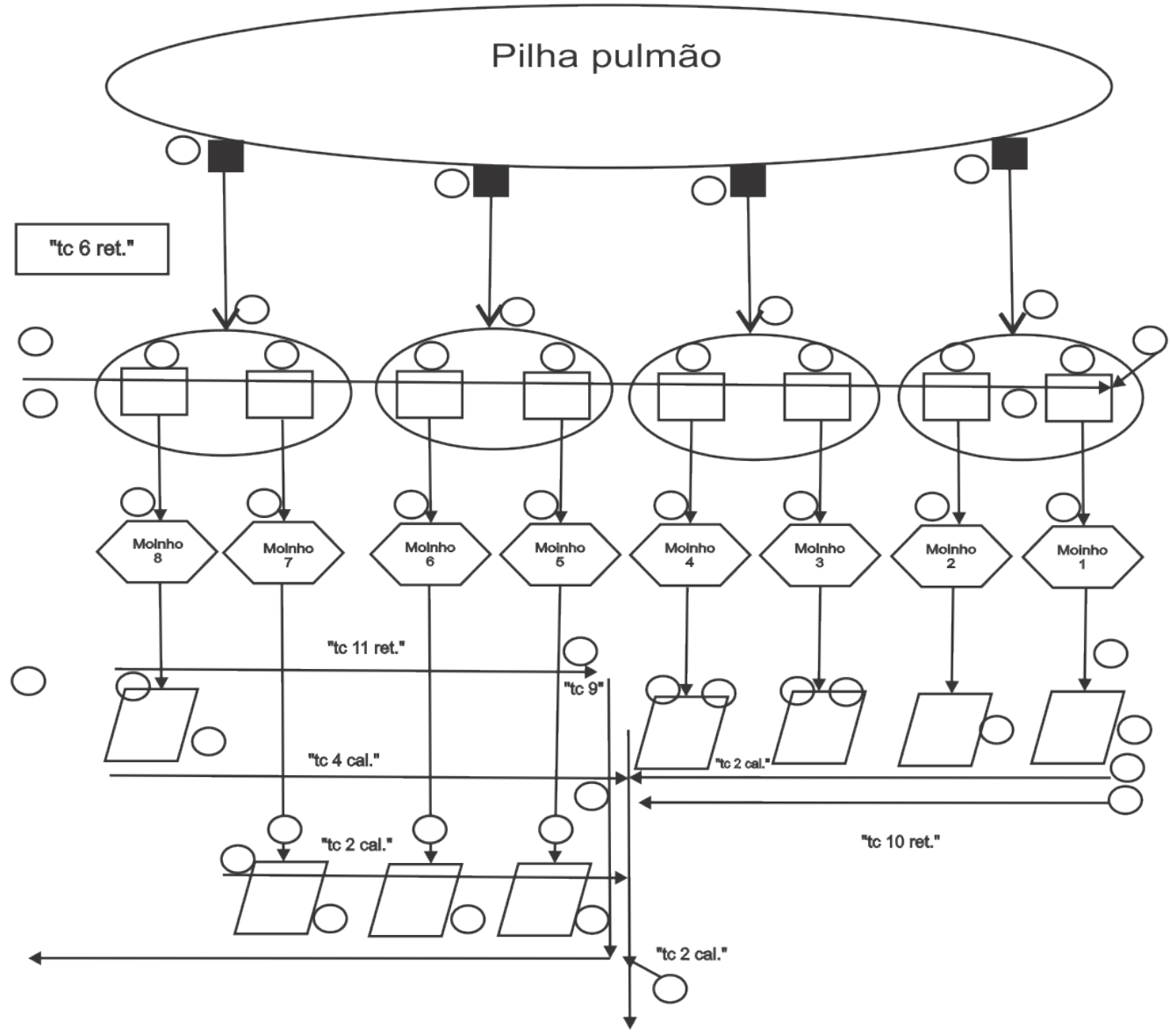

Fonte: Dados da pesquisa (2019).

0 rejeito é direcionado, através de TC, até uma pilha de rejeitos, onde o material é reaproveitado para construção de estradas e aterros, se não possuir uma qualidade química favorável de no mínimo 78,78\% de PN (poder de neutralização).

Em um segundo momento acontece a rebritagem da pedra calcária onde a pedra transportada da pilha pulmão cai em duas calhas alimentadoras pela TC para as peneiras vibratórias de corte para 2in e 3in, para diminuir a quantidade antes de entrar no cone em seu diâmetro de 0 a 3in. Posteriormente, é transportada pela TC para o depósito coberto da pilha pulmão II. Esta etapa é controlada pelo operador de rebritagem. Após, a pedra rebritada do pulmão II cai em quatro gavetas 
alimentadoras que alimentam quatro TC ao pulmão III, onde é controlado pelo alimentador de linha.

Após concluída esta primeira fase, dá-se início a segunda fase que é a moagem e o peneiramento do calcário onde, a partir da pilha pulmão III, saem 8 vibratórias alimentadoras numeradas em sequência, sendo que cada uma possui uma TC que transporta o produto até o moinho.

Após moagem, o calcário vai para as peneiras onde se separa o produto com granulometria desejada através do peneiramento, sendo que nos moinhos 1, 2, 3 e 4 , as peneiras ficam abaixo dos moinhos, descendo por gravidade e nos moinhos 5 , 6, 7 e 8 o transporte até a peneira é realizado por TC.

0 material que não adquire a granulometria desejada vai para central de peneiramento através de TC, onde passa no moinho CP 50 e é peneirado novamente nas peneiras da central de peneiramento que são em total de 6 , ligadas conforme necessidade de produção.

No caso de problemas, manutenção da central de peneiramento ou com o moinho CP 50, o material retorna a pilha pulmão três, através de TC de retorno para ser moído nos mesmos moinhos numerados de 1 ao 8 .

Após peneiramento, o calcário está pronto para o uso. Com ajuda de TC, passa para o silo que, depois de cheio, derrama o produto para o armazenamento no depósito. Com estas informações, foi possível modelar o processo com BPMN, conforme explicado a seguir.

\subsection{MODELAGEM DO PROCESSO}

Durante a fase de modelagem de processos, foi utilizada uma ferramenta digital que demonstrou grande valor, eficiência e facilidade para desenhar, documentar e integrar os elementos do modelo. Neste aspecto, foi possível validar o que afirma Baldam et al. (2007), quando afirma que deseja-se que as ferramentas de modelagem tenham as seguintes características:

a) Facilidade de desenho do processo;

b) Padrões de simbologia prontos para o uso (exemplo: BPMN);

c) Correções de fluxo com facilidade;

d) Integração com bancos de dados e outros sistemas;

e) Possibilidade de agregar informações às atividades (regras, custos, sistemas, documentos gerados, etc.);

f) Publicação dos modelos e documentação em ambiente colaborativo. 
Figura 4 - Diagrama do processo de produção de calcário no modelo BPMN

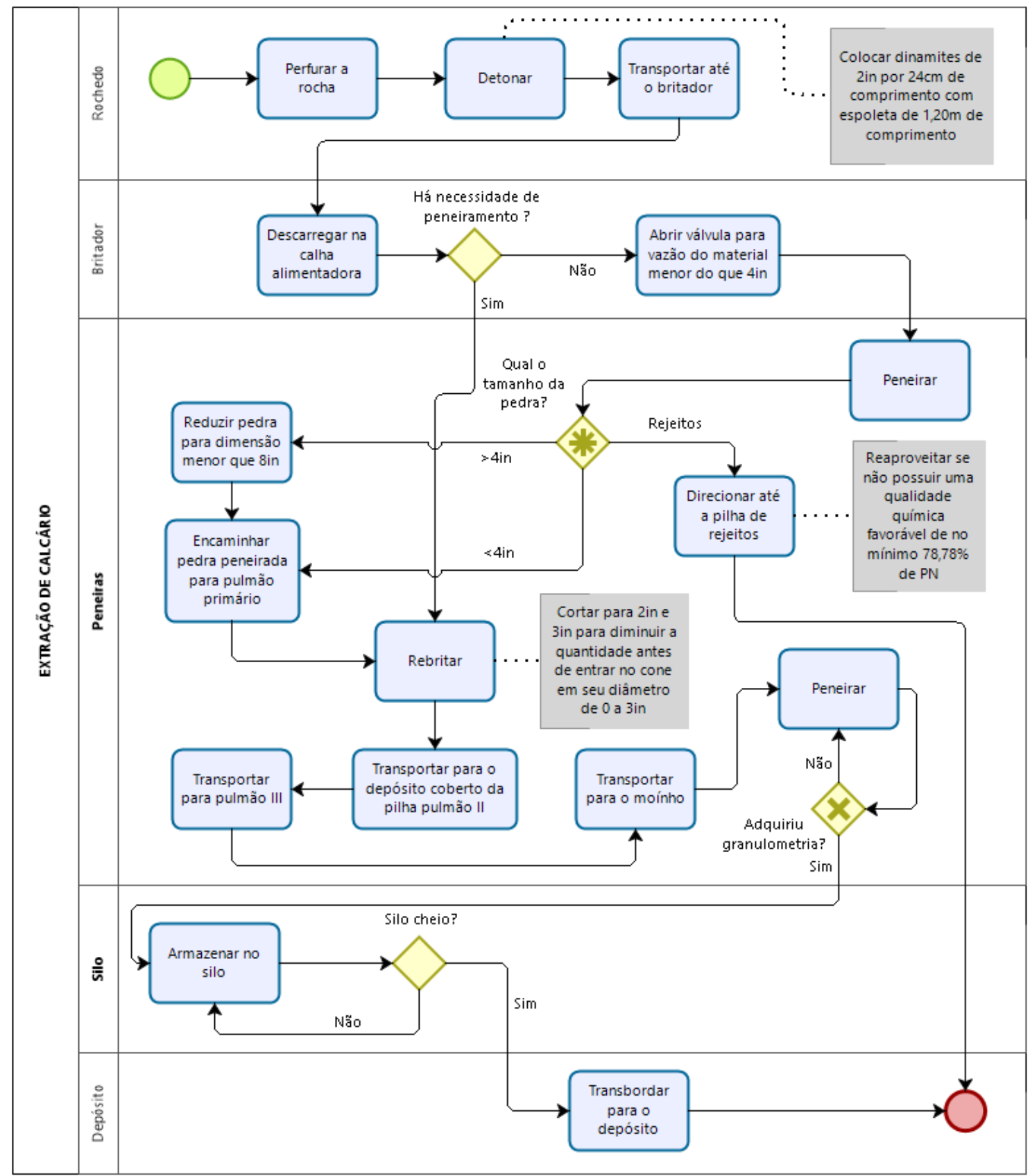

Fonte: Autores (2019).

Neste sentido, Dijkman (2011) afirma que o BPMN é padronizado para a descrição de processos de negócios e combina elementos a partir de um número de padrões anteriormente propostos para modelagem de processos, como por exemplo, os diagramas, fluxogramas de atividade. Desta forma, a Figura 4 apresenta a descrição detalhada do macroprocesso de produção do calcário, composto por elementos básicos que compõe o BPMN e que foram aplicados conforme informações coletadas na empresa em estudo, e desenhado a partir do software BIZAGI. 


\section{CONCLUSÕES}

O objetivo geral deste artigo foi analisar a aplicação do mapeamento de processos produtivos, realizando um estudo de caso em uma empresa do ramo da produção de calcário referente a percepção, aplicabilidade, metodologia e uso das ferramentas de mapeamento de processos. Os resultados verificados com a aplicação da entrevista, na fase final da pesquisa, já indicavam que a empresa possuía uma forma de mapeamento do processo, conhecido por todos os indivíduos da empresa que participam diretamente na produção do calcário e do sistema de produção.

Com a análise dos documentos, visita técnica e entrevista aplicada verificou-se que os resultados obtidos foram expressivos durante todo o período de estudo, superando as expectativas, atingindo uma melhor visualização e entendimento contínuo do processo através da modelagem BPMN o que, permitiu que se alcance uma melhor visualização do macroprocesso produtivo. 0 resultado validou os aspectos teóricos apresentados na referenciada literatura.

A utilização do fluxograma mostrou-se mais vantajosa em macroprocessos, onde se necessita de uma visão global do processo produtivo do calcário. Porém, contendo menos dados e informações com relação aos detalhes e descrição dos mesmos.

A técnica mapa de processo com a utilização do BPMN pôde caracterizar cada atividade do processo, mostrando uma visão mais detalhada. Sendo assim, pode-se dizer que dentre essas técnicas não existe uma superior a outra, mas sim, técnicas mais apropriadas para cada fim e tipo de situação. 0 importante é que estas formas de representação de processos podem ser somadas para um mapeamento mais completo e transparente, fornecendo uma visão mais ampla do processo produtivo com muito mais detalhes.

Portanto, a principal contribuição deste estudo é uma proposta de modelagem dos processos BPMN, exposto e descrito pela literatura, que poderá ser aplicado dentro da organização. 0 mapeamento do processo, através do fluxograma e do mapa de processo, permitiu visualizar na prática as vantagens e desvantagens de cada uma dessas técnicas. 0 objetivo proposto foi alcançado, uma vez que a aplicabilidade e a combinação entre as técnicas foram evidenciadas. 0 artigo demonstrou que ambas as técnicas utilizadas são eficientes em sua proposta de mapear um processo de produção, conservando suas particularidades.

\section{LIMITAÇÕES E SUGESTÃO DE NOVOS ESTUDOS}

A limitação de tempo disponibilizado pelo gestor para participação no processo de pesquisa, no que acabou por gerar poucas informações colhidas durante a entrevista, e os diagramas existentes, os quais não permitiram explicações por parte do pessoal da empresa, foram questões limitantes para o andamento da pesquisa, sem que, no entanto, impossibilitassem a realização da mesma. Sugere-se, para pesquisas futuras, aplicar o modelo proposto tanto no macro e micro processo buscando a comparação dos resultados desta pesquisa em empresas de mesmo 
segmento, diferentes tamanhos e localizações geográficas, a fim de colaborar e ampliar os resultados quanto à percepção do usuário relacionados ao padrão; e também a aprimorar o modelo proposto e contribuir para que os especialistas no padrão possam aperfeiçoar o BPMN.

\section{REFERÊNCIAS}

ABRACAL. Associação Brasileira dos Produtores de Calcário Agrícola. Disponível em: http://www.abracal.com.br/abracal. Porto Alegre, 2015. Acesso em: 18 maio 2018.

AMORIM, Marcos B.; ROCHA, Augusto C. B. Ferramentas de Engenharia de Produção para redução de desperdícios em cozinhas industriais. In: XXXII Encontro Nacional de Engenharia de Produção (Enegep). Anais do (...) - Bento Gonçalves, 2012.

ARANTES, Rhaíssa Nogueira. Introdução ao bussines process modeling notation. Universidade Federal de Goiás, 2014. Disponível: em: www.devmedia.com.br. Acesso em: 13 jun 2018.

BALDAM, Roquemaret al. Gerenciamento de Processos de Negócios: BPM. 1. ed. - São Paulo: Editora Érica, 2007, 240p.

BARDIN, Laurence. Análise de Conteúdo. 1. ed. - São Paulo: Edições 70, 2016.

BORTOLINE, Rafael. Business Process Modeling Notation. Outubro 2006. Disponível em: https://www.smlbrasil.com.br/bpm/a/biblioteca\#bpm. Acesso em: 31 maio 2018.

BROCKE, Jan Vom; ROSEMANN, Michael. Manual de BPM: Gestão de processos de negócio. Porto Alegre: Editora Bookman, 2013.

COSTA, Helder Gomes. Modelo de webibliomining: proposta e caso de aplicação. Revista FAE, Curitiba, v. 13, n. 1, p. 115-126, jan./jun. 2010.

DIJKMAN, R. Similarity of business process models: Metrics and evaluation. Information Systems, v. 36, n. 2, p. 498-516, 2011.

DUBRAY, J. Business process modeling notation. ebPML.org; 2004.

GIL, A. C. Métodos e técnicas de pesquisa social. 5. ed. - São Paulo: Atlas, 2007.

HUNT, V. Daniel. Process mapping: how to reengeneer your business processes. New York: John Wiley \& Sons, Inc., 1996.

LEAL, F.; PINHO, A. F. de; CORRÊA, K. E. S. Análise comparativa de técnicas de mapeamento de processo aplicadas a uma célula de manufatura. Anais XII SIMPEP - Bauru, SP, Brasil, 7 a 9 de novembro de 2005. Disponível em:

https://simpep.feb.unesp.br/anais/anais_12/copiar.php?arquivo=Leal_F_Analise\%20comparativa \%20de.pdf. Acesso em: 16 maio 2018.

LUFT, Celso Pedro. Dicionário prático de regência verbal. São Paulo: Ática, 2013.

MARCONDES. José Sérgio. Gestão de processos organizacionais. 2015. Disponível em:

https://www.gestaodesegurancaprivada.com.br/gestao-de-processos-organizacionais. Acesso em: 16 maio 2018.

MELLO, Carlos Henrique Pereira; SALGADO, Eduardo Gomes. Mapeamento dos processos em serviços: estudo de caso em duas pequenas empresas da área de saúde. In: ENEGEP, 25, 2005. Anais do (...), Porto Alegre, 2005.

MOREIRA, Daniel Augusto. Administração da produção e operações. 2. ed. - São Paulo: Cengage Learning, 2011.

OLIVEIRA. Hugo Miguel Ribeiro. Aplicabilidade da filosofia enxuta em indústrias de processo contínuo: um estudo de caso. Ponta Grossa, 2015.

PINHO, Alexandre Ferreira; LEAL, Fabiano; MONTEVECHI, Jose Arnaldo Barra; ALMEIDA, Dagoberto Alves; Combinação entre as técnicas de fluxograma e mapa de processo no mapeamento 
de um processo produtivo. XXVII Encontro Nacional de Engenharia de Produção. In: ENGEP. Anais do (...), Foz do Iguaçu, 2007.

RECKER, Jan. Opportunities and constraints: the current struggle with BPMN. Information Systems, v. 16, n. 1, p. 181-201, 2010. Disponível em: www.emeraldinsight.com. Acesso em: 13 jun 2018.

SEBRAE. Perfil das cidades gaúchas. 2017. Disponível em: http://ambientedigital.sebraers.com.br/Download/PerfilCidades/Perfil_Cidades_Gauchascacapava_do_sul.pdf. Acesso em: 18 maio 2018.

SLACK, Nigel; BRANDON-JONES, Alistair; JOHNSTON, Robert. Administração da produção. 4. ed. São Paulo: Atlas, 2015.

USIRONO. Carlos Hiroshi. Escritório de Processos. Rio de Janeiro: Brasport, 2015.

VALLE, Rogerio; OLIVEIRA Saulo Barbara. Analise e modelagem de processos de negócios. Foco na notação BPMN. São Paulo: Atlas, 2015.

VENKI. Soluções para gerenciamento de processos de negócios BPN. 2016. Disponível em: http://www.venki.com.br. Acesso em: 1 jun. 2018.

VILLELA. Cristiane da Silva Santos. Mapeamento de processos como ferramenta de reestruturação e aprendizado organizacional. Florianópolis, 2000.

WHITE, Stephen A. Using BPMN to Model a BPEL Process. IBM, New York, 2004. Disponível em: http://www.bpmn.org. Acesso em: 31 maio 2018. 